\title{
rTMS combined with TENS eco2 and rivastigmine improves cognitive functions in Alzheimer disease : Synergistic effect?
}

\author{
Guilloux JL $\mathrm{L}^{1 *}$, Barbar $\mathrm{V}^{2}$ and Bouhroum $\mathrm{S}^{3}$ \\ ${ }^{1}$ Neurologist- Neuromodulation Center - North Parisian Private Hospital- Sarcelles 95200, France \\ ${ }^{2}$ TMS technician - Neuromodulation Center - North Parisian Private Hospital - Sarcelles 95200, France \\ ${ }^{3}$ Project manager - GCS-RISSA (Groupement de Coopération Sanitaire Recherche et Innovation Santé Sarcelles) - Sarcelles 95200, France
}

\begin{abstract}
A 60-year-old patient who was suffering from Alzheimer disease was applied rTMS (repetitive transcranial magnetic stimulation) according to neuroAD procedure combined with TENS eco 2 (transcutaneous electrical nerve stimulator) improved cognitive fonctions. Conclusion : rTMS combined with TENS eco 2 is very promising approach to improve cognitive fonctions in Alzheimer disease. These two neuromodulation techniques might have a synergistic effect.
\end{abstract}

\section{Case Report}

A 60-year-old patient, house painter, was discharged in our hospital because he was suffering from memory impairment, spatiotemporal disorientation since 2 years. He had no medical past and no treatment. At his first visit (March 29th, 2017), his clinic exam showed MMSE (Mini-Mental State Examination) was 19/30, temporal orientation $1 / 5$, spatial orientation $5 / 5$, registration $3 / 3$, attention and calculation $3 / 5$, recall $0 / 3$, language $7 / 9$. HAMD score (Hamilton Depression Rating Scale) was 0/48. Test clock-drawing test was not normal, $5 / 10$, with an error in the hands and numbers positionning. Five-words test was $7 / 10$, encoding $5 / 5$, stocking and consolidation $3 / 5$. He had a gestural apraxia. In summary, his neuropsychologic exam revealed temporal disorientation, hippocampic memory impairment, executive dysfunction, visuo-spatial impairment, and gestural apraxia. Blood sample was normal. Brain MRI showed right hippocampal atrophy and 18-FDG PETscann (F-18 fluorodeoxyglucose positron emission tomography) revealed mild hypometabolism in bilateral mesial prefrontal cortex, bilateral associative parietotemporal cortices more prominent in right and severe hypometabolism in amygdalohippocampic structures. The diagnosis of " probable " Alzheimer disease was realized according to the National Institute of Neurological and Communicative Disorders and Stroke- Alzheimer's Disease and Related Disorders Association criteria [1]. We introduced rivastigmine transdermic patch 4,6 mg per day and at the second visit, after one month, 9,5 mg per day. He refused to make orthophony.

Six months later, he was applied rTMS (repetitive transcranial magnetic stimulation) according to neuroAD procedure [2] during six weeks, 5 days a week. At the third visit, (october 25th, 2017) 2 weeks after rTMS, MMSE was improved and was $21 / 30$, temporal orientation $1 / 5$, spatial orientation $5 / 5$, registration $3 / 3$, attention and calculation $4 / 5$, recall $1 / 3$, language $7 / 9$.

Then, he had used TENS eco 2 (transcutaneous electrical nerve stimulator) with left auricular electrode 2 hours per day, 7 days a week, during three months. At the 4th visit (december 21th, 2017), MMSE was improved and was $24 / 30$, temporal orientation $3 / 5$, spatial orientation $5 / 5$, registration $3 / 3$, attention and calculation $3 / 5$, recall $3 / 3$, language $7 / 9$.

\section{RTMS therapy}

Sessions of rTMS treatment were delivered with a standard $70 \mathrm{~mm}$ figure-of-eight coil (PMD 70 pCool coil), attached to a Powermag 30 Stimulator (Mag\&More, Germany). Using an MRI based frameless stereotactic neuronavigation system (Syneika One, Syneika, France), the center of the TMS coil was positioned tangential to the scalp location overlying (with the shortest distance). The TMS coil was oriented with the handle oriented in an anterior-to-posterior and medial-to-lateral direction according to neuroAD procedure : 6 different brain areas (right and left dorsolateral prefrontal cortex (R/L DLPFC), right and left posterior parietal (R/L PP) cortex associative areas, and Broca and Wernicke language areas). He was applied rTMS on alternation : Day $+1 \mathrm{R} / \mathrm{L}$ DLPFC, R/L PP (+add on R DLPFC 2,5 min), 100\% motor threshold (MT), at frequency of $10 \mathrm{~Hz}, 10$ trains of 40 pulses with intertrain intervalle 40 secondes, Day +2 : L DLPFC, Broca, Wernicke (+add on L DLPFC 2,5 min), 100\% motor threshold (MT), at frequency of $10 \mathrm{~Hz}, 5$ trains of 20 pulses with intertrain intervalle 40 secondes., 5 days a week, during 6 weeks.

The target was identified according to the patient's brain surface anatomical features manually and labeled on a $3 \mathrm{D}$ rendering of the patient's individual T1 MRI sequence. The neuronavigation system recorded the location and after daily spatial calibration taking into

Correspondence to: Guilloux JL, Neurologist - Neuromodulation Center - North Parisian Private Hospital - Sarcelles 95200, France, E-mail : johanleguilloux@ hotmail.fr

Received: March 11, 2018; Accepted: March 23, 2018; Published: March 26 2018 
account specific head fiducial points, allowing the stimulation of the exact same brain area on any new visit.

\section{TENS eco 2 with auricular electrode}

Sessions underwent every day 2 hours a day. The patient applied an electrode in his left ear (concha) to stimulate vagus nerve (ScwaMedico, Germany) during three months. The parameters of stimulation were frequency $25 \mathrm{~Hz}$, pulse width 50 microsecondes, intensity $9,5 \mathrm{~mA}$ (U-03 program).

\section{Discussion}

Alzheimer's disease (AD) is the most common of dementia, especially in the elderly populations, and the prevalence of $\mathrm{AD}$ is always increasing in recent years [3]. The characteristics of AD show cognitive deficits : memory impairment, language, visuospatial attention, or executive dysfunctions due to accumulation of beta-amyloid plaques and neurofibrillary tangles [4]. These deposites may affect neural networks function especially between the frontal lobes, the cingulate cortex, and posterior parietal and temporal regions [5].

Despite all research efforts, therapeutic options for $\mathrm{AD}$ are still limited. We could propose cognitive training and cholinesterase inhibitors, like donepezil and rivastigmine but it's necessary to developp new other treatment strategies, like non-invasive brain stimulation (NIBS) techniques, in order to enhance cognitive function or to potentiate cognition improvement by combining drugs and cognitive training.

Cognitive training improves cognitive function by activation of neural networks, included the frontal, temporal and parietal areas [6]. In our case, the patient refused orthophony. And donepezil, usually prescribed, improves also cognitive functions, particularly MMSE, by enhancing functional connectivity in orbito-frontal circuit, following 12 weeks of treatment [7,8]. We suppose that rivastigmine, as cholinesterse inhibitor, has the same action than donepezil on the orbito-frontal network.

Recently, NIBS techniques have emerged like rTMS and the transcutaneous vagus nerve stimulation, (ta-VNS).

rTMS is a NIBS method, which could modulate neuroplasticty and is knowm to enhance cognitives functions in $\mathrm{AD}$ over extended periods, beyond the time of stimulation. According to Nguyen et all., neuroAD procedure combined with cognitive training improves cognitive performances (memory, executive functions, language), apathy and dependence following 5 weeks of treatment and its effect is extended to 6 months $[9,10]$.

Then, TENS eco 2 with auricular electrode, new NIBS procedure, consists in stimulating an auricular branch of vagus nerve and activates cortical-limbic-thalamic-striatal neural networks, whom the nucleus tractus solitari, connected with other brain regions, such as the locus coeruleus, parabrachial nucleus, hypothalamus, thalamus, amygdala, hippocampus, anterior cingulate cortex anterior insula, and lateral prefrontal cortex and increases BOLD signal in the contralateral postcentral gyrus, bilateral insula, frontal cortex, right operculum, and left cerebellum $[11,12]$. Indeed, ta-VNS is a treatment for refractory epilepsy and depression, but is known to improve memory [13]. According to Merill et al., after one year with invasive VNS, 7 (41.2\%) of 17 patients and $12(70.6 \%)$ of 17 patients improved or did not decline from baseline on the ADAS-cog (Alzheimer's DiseaseAssessment Scale-cognitive subscale) and MMSE [14].
In our case, MMSE increased by 3 points 2 weeks after neuroAD procedure and 3 points more after 3 months of ta-VNS. We suppose that the combination of both NIBS techniques, rTMS and ta-VNS, enhances cognitive functions in this $\mathrm{AD}$ patient and has an effect synergistic.

\section{Conclusion}

rTMS and ta-VNS may have a potential synergistic effect and potentiate improvement of cognitive functions in $\mathrm{AD}$. More larger studies are warrented to study the efficacy of rTMS combined with taVNS and to identify the optimal stimulation parameters and duration of taVNS

\section{References}

1. McKhann GM, Knopman DS, Chertkow H, Hyman BT, Jack CR Jr, et al. (2011) The diagnosis of dementia due to Alzheimer's disease: recommendations from the National Institute on Aging-Alzheimer's Association workgroups on diagnostic guidelines for Alzheimer's disease. Alzheimers Dement 7: 263-269. [Crossref]

2. Bentwich J, Dobronevsky E, Aichenbaum S, Shorer R, Peretz R, et al. (2011) Beneficial effect of repetitive transcranial magnetic stimulation combined with cognitive training for the treatment of Alzheimer's disease: a proof of concept study. J Neural Transm (Vienna) 118: 463-471. [Crossref]

3. Wimo A, Ljunggren G, Winblad B (1997) Costs of dementia and dementia care: review. Int J Geriatr Psychiatry 12: 841-856. [Crossref]

4. Hardy J (2006) Alzheimer's disease: the amyloid cascade hypothesis: an update and reappraisal. J Alzheimers Dis 9: 151-153. [Crossref]

5. Chhatwal JP, Schultz AP, Johnson KA, Hedden T, Jaimes S, et al. (2018) Preferentia degradation of cognitive networks differentiates Alzheimer's disease from ageing. Brain. [Crossref]

6. Belleville S, Clément F, Mellah S, Gilbert B, Fontaine F, et al. (2011) Training-related brain plasticity in subjects at risk of developing Alzheimer's disease. Brain 134: 1623 1634. [Crossref]

7. Ma Y, Ji J, Li G, Yang S, Pan S (2018) Effects of donepezil on cognitive functions and the expression level of B-amyloid in peripheral blood of patients with Alzheimer's disease. Exp Ther Med 15: 1875-1878. [Crossref]

8. Griffanti L, Wilcock GK, Voets N, Bonifacio G, Mackay CE, et al. (2016) Donepezi Enhances Frontal Functional Connectivity in Alzheimer's Disease: A Pilot Study. Dement Geriatr Cogn Dis Extra 6: 518-528. [Crossref]

9. Nguyen JP, Suarez A, Le Saout E, Meignier M, Nizard J, et al. (2018) Combining cognitive training and multi-site rTMS to improve cognitive functions in Alzheimer's disease. Brain Stimul 18: 30076-30077 [Crossref]

10. Nguyen JP, Suarez A, Kemoun G, Meignier M, Le Saout E, et al. (2017) Repetitive transcranial magnetic stimulation combined with cognitive training for the treatment of Alzheimer's disease. Neurophysiol Clin 47: 47-53. [Crossref]

11. Badran BW, Dowdle LT, Mithoefer OJ, LaBate NT, Coatsworth J, et al. (2017) Neurophysiologic effects of transcutaneous auricularvagus nerve stimulation (taVNS) via electrical stimulation of the tragus: A concurrent taVNS/fMRI study and review. Brain Stimul 17 : 31025-31032. [Crossref]

12. Kong J, Fang J, Park J, Li S, Rong P (2018) Treating Depression with Transcutaneous Auricular Vagus Nerve Stimulation: State of the Art and Future Perspectives. Front Psychiatry 9: 20. [Crossref]

13. Cimpianu CL, Strube W, Falkai P, Palm U, Hasan A (2017) Vagus nerve stimulation in psychiatry: a systematic review of the available evidence. J Neural Transm (Vienna) 124: 145-158. [Crossref]

14. Merrill CA, Jonsson MA, Minthon L, Ejnell H, C-son Silander H, et al. (2006) Vagus nerve stimulation in patients with Alzheimer's disease: Additional follow-up results of a pilot study through 1 year. $J$ Clin Psychiatry 67: 1171-1178. [Crossref]

Copyright: (C2018 Guilloux JL. This is an open-access article distributed under the terms of the Creative Commons Attribution License, which permits unrestricted use, distribution, and reproduction in any medium, provided the original author and source are credited. 